\title{
ANALYSIS OF IMPACT BEHAVIOUR OF TIG WELDMENT BY USING HYBRID RSM AND CSO
}

\author{
MOI Subhas Chandra ${ }^{1}$, RUDRAPATI Ramesh ${ }^{2}$, PAL Pradip Kumar ${ }^{3}$, \\ BANDYOPADHYAY Asish ${ }^{4}$ \\ 1, 3,4 Jadavpur University, Department of Mechanical Engineering, Kolkata - 700032, India, \\ e -mail: sc_moil@rediffmail.com,pradippal54@yahoo.com,asishbanerjee@yahoo.com, \\ Research Scholar ${ }^{1}$, Ex-Professor ${ }^{3}$, Professor $^{4}$ \\ ${ }^{2}$ Hawassa University, Department of Mechanical Engineering, Ethiopia \\ e - mail: ramesh.rudrapati@gmail.com, Assistant Professor
}

\begin{abstract}
Tungsten inert gas (TIG) welding is a multi-input and multi-output variant process. The input process parameters and other factors of welding process interact in a complicated manner and influence the weld quality - directly or indirectly. Keeping this in mind, the present work has been planned to study the impact behaviour of TIG weldment through experiments, analysis and optimization. Experimental runs have been considered as per Box-Behnken design of response surface methodology (RSM). Based on the recorded data, the mathematical models have been developed to study the effect of process parameters on impact strength. ANOVA has been utilized to identify the influence of input process parameters on the response i.e. impact strength. RSM and cuckoo search optimization (CSO) algorithm have also been applied to optimize the impact strength.
\end{abstract}

KEYWORDS: Tungsten inert gas welding, RSM, CSO, Impact strength

\section{Introduction}

Tungsten inert gas welding is one of the most efficient and widely used technique for joining similar and dissimilar metals compared to other welding techniques such as metal inert gas (MIG), submerged arc welding (SAW), laser welding etc., because of high welding quality, high stability in welding of variety of metals for various industrial applications $[1,2$, $3,4]$. In the area of TIG welding of stainless steel and also in respect of effect of process parameters on the quality of weld is an important area of research [5] due to corrosion and crack formation resistance [6].

Like any other welding processes, TIG welding needs to be done with proper selection of welding process parameters and its levels which can play very important role in determining the desired quality or in other words, the mechanical properties which includes hardness, tensile strength, fatigue strength etc of the welded joint [7]. The important parameters are welding current, arc voltage, electrode size, wire feed rate arc travel speed, electrode stick out etc. And further the quality of weld in TIG may be affected due to welding position, electrode composition, edge preparation, the type of gases used and its flow rate. Analyzing and understanding the effects of process variables on output responses like impact strength is very important for obtaining best possible weld quality in TIG welding. Impact strength is one the most important quality response of any welded structure like aircraft, bridge etc. Impact strength is the resistance of a material to fracture under a sudden impact, or shock load. It signifies the product performance, service life, and liability [8, 9].

The systematic analysis and optimization approaches are required to prepare good quality of welded joint and to enhance the quality responses of joining materials [10]. Though a lot of 
publications are available on optimization and still coming out on process optimization in different fields of manufacturing [11], a lot more needs to be done. Because each study is done within a range of input parameters, considering variation of selected input parameters, for a specific thickness for work material with one or two different filler materials and emphasizing on certain aspects only. Thus extensive research, covering wide ranges of different factors - directing towards various aspects, by many investigators - will ultimately create a reliable, precise data bank and knowledge accumulation. Further, there are different well established optimization techniques, but RSM is still one the most efficient and widely used statistical methods for analyzing, modelling and optimization of various processes [12, 13 ] and it is used for solving single objective problems as well as multi-objective problems.

Statistical based robust parameter design of RSM is very useful for planning the experiments and to study and control the input parameters of manufacturing processes / systems. Response surface methodology (RSM) is useful statistical tool to generate mathematical relations between the input parameters and output responses [14, 15]. Vasantharaja and Vasudevan [16] has been conducted experimental analysis on activated TIG welding to determine the effects of process welding variables on bead shape parameters: depth of penetration, bead width and heat affected zone width, using RSM and DFA. The quadratic polynomial mathematical model was created for optimizing responses for a given set of welding process parameters. Researchers found better weld joint quality responses with integrated RSM and DFA. Kiaee and Aghaie-Khafri [17] have studied the simultaneous effects of gas tungsten arc welding process parameters on tensile strength and hardness on A516-70 carbon steel by response surface methodology. They found the optimum tensile strength and hardness at optimum current of $130 \mathrm{~A}$, welding speed of $9.4 \mathrm{~cm} / \mathrm{min}$ and gas flow rate of $15.1 \mathrm{l} / \mathrm{min}$. Martinez-Conesa et al. [18] have applied RSM to predict the optimal dimensions of bead geometry obtained in butt welded joint by gas metal arc welding. Cuckoo search optimization (CSO) algorithm is a nature inspired optimization procedure which is treated as intelligent technique used by researchers to solve the engineering problems. Dao et al. [19] had been optimized the design variables of compliant focus-positioning platform (CFPP) using integrated Taguchi method and cuckoo search algorithm. ANOVA was also used to determine the effects of design variables on quality responses. Researchers were found better quality responses for the CFPP using hybrid Taguchi-cuckoo search algorithm. Azizah [20] had been applied the applications of cuckoo search algorithm (CSA) to optimize the surface roughness in abrasive water jet machining (AWJ) process. The author stated that CSA was very useful to optimize the cutting conditions of AWJ machining. S. Burnwal et.,al [21] developed cuckoo search based approach for scheduling optimization of flexible manufacturing system by minimizing penalty cost due to delay in manufacturing and maximizing machine utilization time.

From literature study it is observed that many researchers have been focused on various aspects of welded joints including microstructural analysis, mechanical properties and corrosion resistance of stainless steel. But very few research works have been reported to analyze and optimize TIG welding process parameters to obtain better weld quality in terms of impact strength of 316L austenitic stainless steel joint. As impact strength is a very important phenomenon in governing the life of any structural members/bodies and it is the capability of the material to withstand a suddenly applied load. Therefore, the present work has been planned to study the impact behaviour of TIG weldment of 316L austenitic stainless steel through experiments, analysis and optimization using hybrid response surface methodology and cuckoo search optimization technique. 


\section{Response surface methodology (RSM)}

Response surface methodology is one of the most important and popular optimization techniques in use today. It is a collection of mathematical and statistical techniques useful for the modelling and analysis of engineering problems in which a response of interest is influenced by several variables and the objective is to optimize or minimize this response. For first order response surface model for the case of three independent variables is expressed as follows:

$$
Y=b_{0}+b_{1} x_{1}+b_{2} x_{2}+b_{3} x_{3}+€
$$

Usually, a second order polynomial equation is used in RSM that is given below:

$$
\mathrm{Y}=b_{0}+\sum_{i=1}^{k}\left(b_{i} x_{i}\right)+\sum_{i=1}^{k}\left(b_{i i} x_{i}^{2}\right)+\sum \sum\left(b_{i j} x_{i} x_{j}\right)+€
$$

where, $\mathrm{Y}=$ response variables i.e. dependent variables

$x_{i}=$ predicted variables i.e. independent variables

$b_{0}=$ model constant

$€=$ random error

parameters $b_{i}, b_{i i}, b_{i j}$ are known as regression coefficient, where $\mathrm{i}=1,2,3, . . \mathrm{k}$ and $\mathrm{j}=1,2,3, \ldots \mathrm{k}$.

\section{Experimentation}

AISI 316L stainless steel plates of thickness $3 \mathrm{~mm}$ has been selected as work piece material. ER316L austenitic stainless steel of diameter $1.6 \mathrm{~mm}$ has been taken as a filler material. The chemical composition of the work piece material and filler material is given in Table 1. The Box-Behnken experimental design based on RSM approach has been used to plan the experiments by considering welding current (A), welding speed (B) and gas flow rate (C) as input process parameters for TIG welding of austenitic stainless steel material. The selected input parameters and their varying levels are: welding current $(\mathrm{A})=100 \mathrm{~A}, 125 \mathrm{~A}$ and $150 \mathrm{~A}$, welding speed $(\mathrm{B})=12,15$ and $18 \mathrm{~cm} / \mathrm{min}$ and gas flow rate $(\mathrm{C})=6,9$ and $12 \mathrm{l} / \mathrm{min}$. Trial experiments and research papers are referred to decide the range of welding parameters. Square butt joint configurations have been prepared by SUPERGEN 320 TIG welding machine using argon with purity $99.99 \%$, as shielding gas. To avoid distortion, the work pieces have been placed on copper plate and mechanical clamps are also used during welding as shown in Fig. 1.

Table 1 Chemical composition of the base material, filler material and weld metal

\begin{tabular}{|l|c|c|c|c|c|c|c|c|c|c|}
\hline Weight \% & $\mathrm{C}$ & $\mathrm{Mn}$ & $\mathrm{Si}$ & $\mathrm{S}$ & $\mathrm{P}$ & $\mathrm{Cr}$ & $\mathrm{Ni}$ & $\mathrm{Mo}$ & $\mathrm{Cu}$ & $\mathrm{Fe}$ \\
\hline AISI 316L & 0.026 & 0.97 & 0.26 & 0.012 & 0.043 & 16.12 & 10.08 & 2.03 & 0.15 & 70.31 \\
\hline ER 316L & 0.040 & 1.50 & 0.45 & 0.030 & 0.030 & 18.20 & 12.00 & 2.30 & 0.75 & 64.70 \\
\hline
\end{tabular}

The Box-Behnken experimental design is used to conduct the experiments. Box-Behnken design is used to generate higher order response surfaces using fewer required runs than a normal factorial technique and it also permit estimation of the parameters of the quadratic model, building of sequential designs and detection of lack of fit of the model [22]. After completion of experimental runs, Charpy impact test specimens have been prepared in accordance with ASTM E23 as shown in Fig. 2 and tests have been conducted by impact tester machine (Make-S. D. HARDSON \& CO., Model - SDH/100). Impact tests are used in 
studying the toughness of material/weld material. A material's toughness is a factor of its ability to absorb energy during plastic deformation. The measured response i.e. impact strength of all the samples is listed in Table 2.

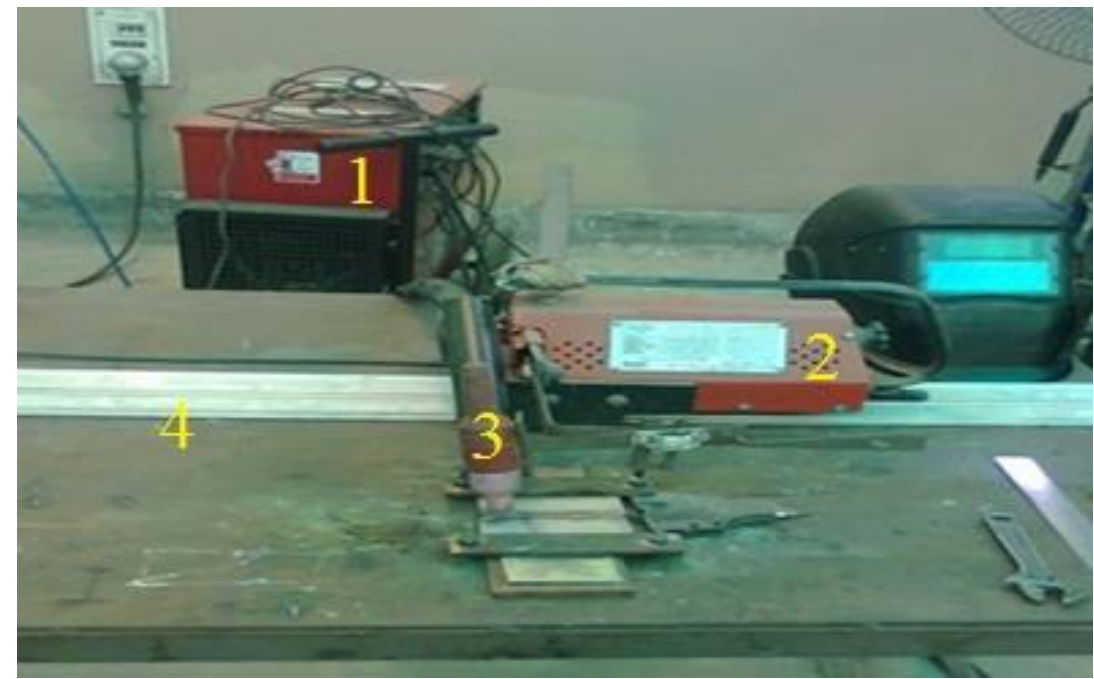

1-welding machine, 2-travel car, 3-TIG torch, 4- track

Fig. 1 Photographic view of experimental setup

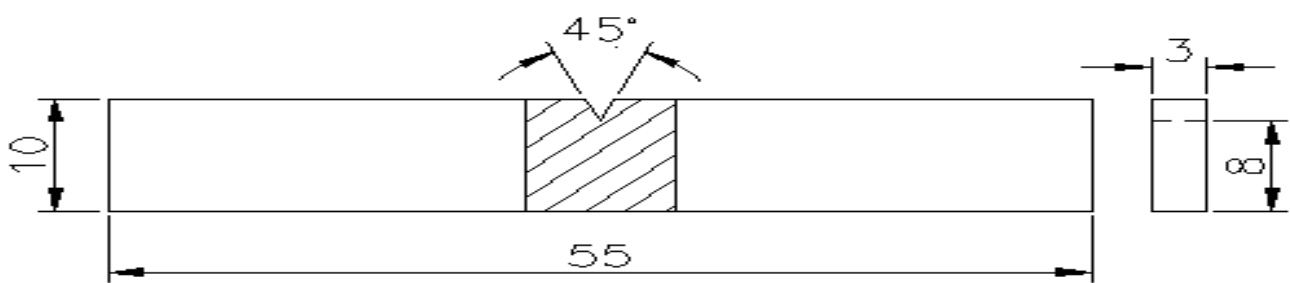

Fig. 2 Impact test specimen

Table 2 Experimental design matrix and output response

\begin{tabular}{|c|c|c|c|c|}
\hline Sp.No. & $\begin{array}{c}\text { Current } \\
\text { (A) }\end{array}$ & $\begin{array}{c}\text { Speed } \\
(\mathrm{cm} / \mathrm{min})\end{array}$ & $\begin{array}{c}\text { GFR } \\
(\mathrm{l} / \mathrm{min}\end{array}$ & $\begin{array}{c}\text { Impact strength } \\
(\mathrm{J})\end{array}$ \\
\hline 1 & 100 & 12 & 9 & 41.5 \\
2 & 150 & 18 & 9 & 45.5 \\
3 & 125 & 18 & 6 & 39.5 \\
4 & 125 & 18 & 12 & 42.5 \\
5 & 125 & 15 & 9 & 51.5 \\
6 & 150 & 12 & 9 & 39 \\
7 & 100 & 15 & 12 & 33.5 \\
8 & 100 & 15 & 6 & 41 \\
9 & 100 & 18 & 9 & 40.5 \\
10 & 150 & 15 & 12 & 40 \\
11 & 125 & 12 & 12 & 35 \\
12 & 125 & 15 & 9 & 51 \\
13 & 125 & 15 & 9 & 51.5 \\
14 & 150 & 15 & 6 & 38 \\
15 & 125 & 12 & 6 & 42 \\
\hline
\end{tabular}




\section{$4 \quad$ Result and Discussion}

\subsection{ANOVA}

Analysis of variance is a statistical tool which useful to analyse the effects of TIG welding process parameters on its performance characteristics. In the present work, analysis of variance has been performed on experimental data at 95\% confidence level i.e. 5\% significance level. The result of ANOVA for impact strength is shown in Table 3.

The ANOVA indicates that for impact strength, the welding current (A), welding speed (B), gas flow rate $(C)$, the quadratic effect of the welding current $\left(\mathrm{A}^{2}\right)$, welding speed $\left(\mathrm{B}^{2}\right)$ and gas flow rate $\left(\mathrm{C}^{2}\right)$, interaction effect of welding current and speed (A x B), welding current and gas flow rate $(\mathrm{A} \times \mathrm{C})$, welding speed and gas flow rate $(\mathrm{B} \times \mathrm{C})$, are the significant model terms as the P-values are less than 0.05. The lack of fit value of 0.681 implies that the lack of fit is not significant relative to the pure error and it is good. The 'R-squared' value is 0.9978 and 'Predicted R-squared' of 0.9805 is in reasonable agreement with the 'Adjusted Rsquared' of 0.9937.

Table 3 ANOVA results for testing adequacy of the impact strength

\begin{tabular}{lrrrrr}
\hline Source & DF & Adj SS & Adj MS & F-Value & P-Value \\
\hline Model & 9 & 416.463 & 46.274 & 246.79 & 0.000 \\
Linear & 3 & 23.938 & 7.979 & 42.56 & 0.001 \\
Current & 1 & 2.531 & 2.531 & 13.50 & 0.014 \\
Speed & 1 & 11.281 & 11.281 & 60.17 & 0.001 \\
Gas Flow Rate & 1 & 10.125 & 10.125 & 54.00 & 0.001 \\
Square & 3 & 340.963 & 113.654 & 606.16 & 0.000 \\
Current*Current & 1 & 119.438 & 119.438 & 637.00 & 0.000 \\
Speed*Speed & 1 & 72.707 & 72.707 & 387.77 & 0.000 \\
Gas Flow Rate*Gas Flow Rate & 1 & 197.438 & 197.438 & 1053.00 & 0.000 \\
2-Way Interaction & 3 & 51.563 & 17.188 & 91.67 & 0.000 \\
Current*Speed & 1 & 10.563 & 10.563 & 56.33 & 0.001 \\
Current*Gas Flow Rate & 1 & 16.000 & 16.000 & 85.33 & 0.000 \\
Speed*Gas Flow Rate & 1 & 25.000 & 25.000 & 133.33 & 0.000 \\
Error & 5 & 0.938 & 0.188 & & 0.681 \\
Lack-of-Fit & 3 & 0.438 & 0.146 & 0.58 & 0.000 \\
Pure Error & 2 & 0.500 & 0.250 & & \\
Total & 14 & 417.400 & & & \\
\hline
\end{tabular}

Model Summary

$\begin{array}{lclc}\text { S } & \text { R-sq } & \text { R-sq(adj) } & \text { R-sq(pred) } \\ 0.433013 & 99.78 \% & 99.37 \% & 98.05 \%\end{array}$

\subsection{Developing the Mathematical Model}

The second order regression equations for the responses in terms of coded factors are given below:

$$
\begin{aligned}
\text { Impact toughness }(\mathrm{J}) & =-164.7+1.733 \text { Current }+9.979 \text { Speed }+ \\
& +6.750 \text { Gas Flow Rate }-0.009100 \text { Current*Current }- \\
& -0.4931 \text { Speed } * \text { Speed }-0.8125 \text { Gas Flow Rate } * \\
& * \text { Gas Flow Rate }+0.02167 \text { Current*Speed }+ \\
& +0.02667 \text { Current*Gas Flow Rate }+ \\
& +0.2778 \text { Speed } * \text { Gas Flow Rate }
\end{aligned}
$$




\subsection{Model validation}

The soundness of the developed model has also been checked by the normal probability plot of the residuals for impact strength as shown in Fig. 3. From figure it is seen that the residuals fall on the straight line, which means the errors are distributed normally and the mathematical relationship is correctly developed.

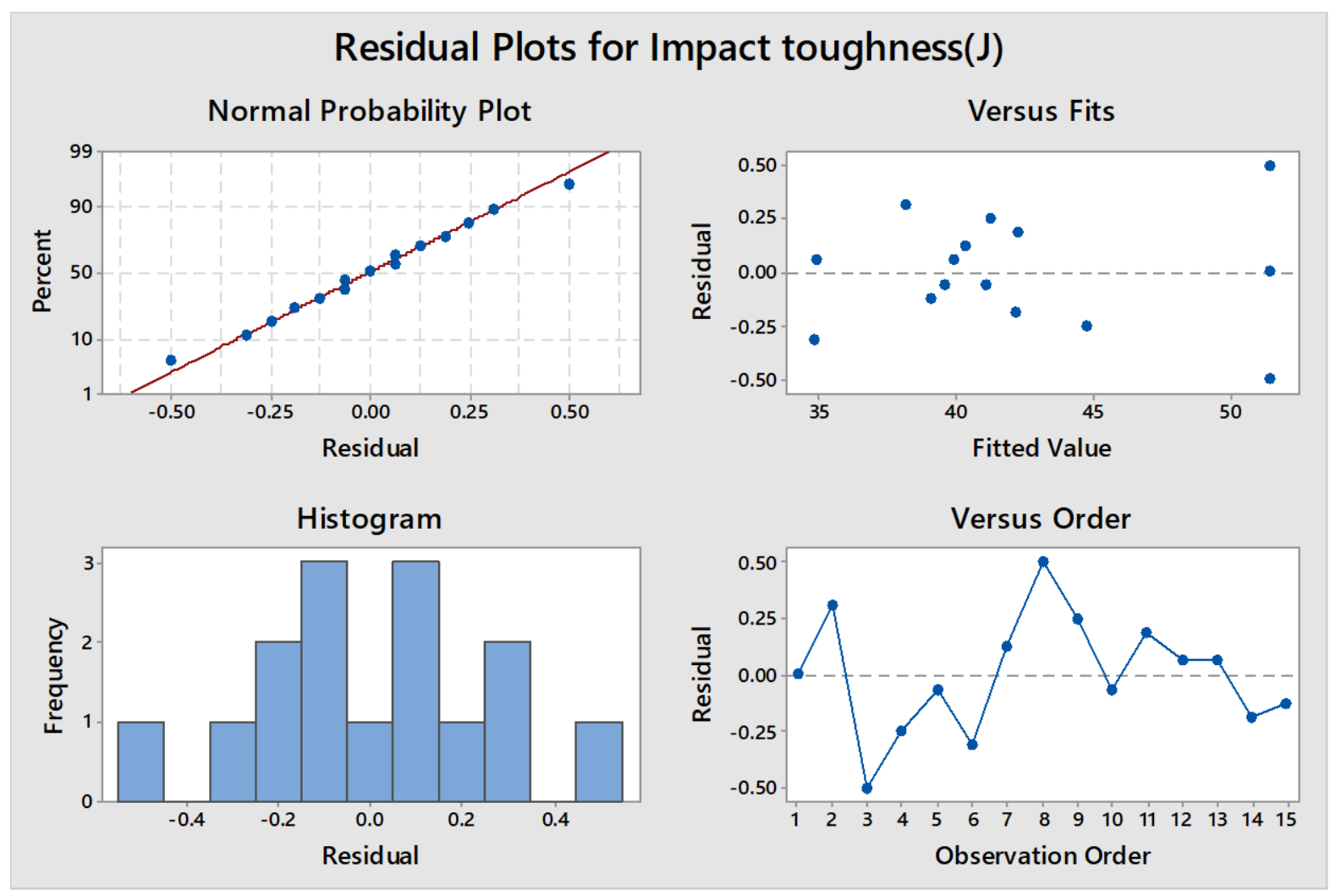

Fig. 3 Residual plots for Impact strength

\section{Optimization by Cuckoo Search Optimization (CSO) Algorithm}

Cuckoo search optimization (CSO) is one of the well-known evolutionary techniques in global optimization. It is a probability based meta-heuristic optimization technique which was proposed by Yang and Deb [23]. CSO is a bio-based algorithm which developed by inspired from the curious breeding behavior of cuckoo birds. Cuckoo birds having different characteristics compared to other birds. The main distinctive features of cuckoo birds have aggressive reproduction strategy by replacing their eggs in other birds' nests to increase their population. The survival endeavor of cuckoos converges to a society in which each cuckoo has same fitness value. Thus, CSO algorithm has been recognized to handle the complex optimization problems, effectively. The main advantage of this search algorithm is its simplicity, rapid convergence and efficiency in solving highly non-linear optimization problems with real-world engineering applications [24,25] and better performance than many other agent or population based meta heuristic algorithms like, genetic algorithm, particle swarm optimization etc. [26].

The CSO algorithm starts with random search called Levy flights in which the step-lengths are distributed according to a heavy-tailed probability distribution. Specifically, the distribution used is a power law of the form $\mathrm{y}=\mathrm{x} 20$, where $1<\mathrm{a}<3$, and therefore has an infinite variance. 
Pseudo-code for CSO algorithm is given as follows [27]:

a. Start

b. Objective function $\mathrm{f}(\mathrm{x}), \mathrm{x}=(\mathrm{x} 1 \mathrm{f} \ldots, \mathrm{xd})^{\mathrm{T}}$;

c. Initialize a population of $n$ host nests $x,(/=1,2, \ldots, n)$;

d. while ( $\mathrm{t}<$ Maximum Generation) or (not stop criterion)

e. Get a cuckoo (say i) randomly and generate a new solution by Levy flights;

f. Evaluate its quality/fitness, Fi,

g. Choose a nest among $\mathrm{n}$ (say j) randomly;

h. if $(\mathrm{Fi}>\mathrm{Fj})$;

i. Replace $\mathrm{j}$ by the new solution;

j. End if

k. Abandon a fraction (pd) of worst nests, and build new ones at new locations via Levy flights;

1. Keep the best solutions;

$\mathrm{m}$. Sort the solutions and find the current best;

n. End while

o. Post processing and visual representation.

The CSO program is run in MATLAB environment and obtained the solution $n$ from the mathematical model as given in Eq. 3 for TIG welding of 316L stainless steel. The obtained optimum parametric setting is: welding current $(\mathrm{A})=126.62 \mathrm{~A}$, welding speed $(\mathrm{B})=15.39 \mathrm{~cm}$ $/ \mathrm{min}$, gas flow rate $(\mathrm{C})=8.85 \mathrm{l} / \mathrm{min}$ and corresponding impact strength $=51.62 \mathrm{~J}$.

\section{Confirmation Test}

The result of optimization has been validated by performing confirmatory test. Three tests have been performed at optimum parametric condition and average results are tabulated in Table 4. It is observed from Table 4 that the percentage error between the predicted and experimental results is very small. And it is within the satisfactory range of percentage errors.

Table 4 Optimization validation test result

\begin{tabular}{|ccccc|}
\hline \multicolumn{3}{|c}{ Optimum condition } & & Response \\
\hline $\mathrm{A}(\mathrm{A})$ & $\mathrm{B}(\mathrm{cm} / \mathrm{min})$ & $\mathrm{C}(1 / \mathrm{min})$ & & Impact strength $(\mathrm{J})$ \\
\hline 126.62 & 15.39 & \multirow{2}{*}{8.85} & Avg. Actual & 52.00 \\
& & & Predicted & 51.62 \\
& & & | Error \% & 0.74 \\
\hline
\end{tabular}

\section{CONCLUSIONS}

The conclusions which are drawn from the experimental results, their interpretations and analyses, are as follows:

The most significant factor affecting impact strength is welding speed. Next significant factors in this respect are gas flow rate and welding current respectively.

* Second order mathematical model is developed for postulating relationships between input process parameters and output responses by RSM approach. 
* Optimal parametric setting and corresponding output response i.e. impact strength (J) predicted by CSO algorithm is: welding current $(\mathrm{A})=126.62 \mathrm{~A}$, welding speed $(\mathrm{B})=$ $15.39 \mathrm{~cm} / \mathrm{min}$, gas flow rate $(\mathrm{C})=8.851 / \mathrm{min}$ and corresponding impact strength $=$ $51.62 \mathrm{~J}$.

\section{REFERENCES}

[1] Harb, A. A., Ciuca, I., Ciocoiu, R., Vasile, M., Adrian, B., Rahali, B., Al Hawamda, I. "Effect of TIG welding and manual metal arc welding on mechanical properties of AISI 304 and 316L austenitic stainless-steel sheets", Key Engineering Materials 750, pp. 26 33, 2017. DOI: 10.4028/www.scientific.net/KEM.750.26

[2] Santillana, I. A., Boyer, C., Pison, P. F., Foussat, A., Langeslag, S. A. E., Fontenla, A. T. P., Ruiz Navas, E. M., Sgobba, S. "A comparative study of fracture toughness at cryogenic temperature of austenitic stainless-steel welds", Journal of Materials Engineering and Performance 27 (4), pp. 1995 - 2002, 2018. DOI: 10.1007/s11665018-3266-1

[3] Ugur, E., Melih, B, Yugut, K., Sueda, O. "Optimization of weld bead geometry in TIG welding process using grey relation analysis and Taguchi method", Materials and Technology 43 (3), pp. 143 - 149, 2009.

[4] Tarng, Y. S., Yang, W. H. "Optimisation of the weld bead geometry in gas tungsten arc welding by the Taguchi method", The International Journal of Advanced Manufacturing Technology 14 (8), pp. 549 - 554, 1998.

[5] Juang, S. C., Tarng, Y. S. "Process parameter selection for optimizing the weld pool geometry in the tungsten inert gas welding of stainless steel", Journal of Materials Processing Technology 122 (1), pp. 33 - 37, 2002.

[6] Rudrapati, R., Chowdhury, N., Bandyopadhyay, A. "Parametric optimization of TIG welding process in butt joining of mild steel and stainless steel", International Journal of Current Engineering and Technology 6, pp. 144 - 149, 2016.

[7] Bodkhe, S. C., Dolas, D. R. "Optimization of activated tungsten inert gas welding of 304L austenitic stainless steel”, Procedia Manufacturing 20, pp. 277 - 282, 2018.

[8] Amudarasan, N. V., Palanikumar, K., Shanmugam, K. "Impact behaviour and Micro structural analysis of AISI 316L stainless steel weldments", International Journal of Application or Innovation in Engineering \& Management 2 (6), pp. 269 - 272, 2013.

[9] Zou, Y., Ueji, R., Fujii, H. "Mechanical properties of advanced active-TIG welded duplex stainless steel and ferrite steel", Materials Science and Engineering: A 620, pp. 140 - 148, 2015. DOI: 10.1016/j.msea.2014.10.006

[10] Gardner, L. "The use of stainless steel in structures", Progress in Structural Engineering and Materials 7 (2), pp. $45-55,2005$.

[11] Selvaraj, D. P., Chandramohan, P., Mohanraj, M. "Optimization of surface roughness, cutting force and tool wear of nitrogen alloyed duplex stainless steel in a dry turning process using Taguchi method", Measurements 49, pp. 205 - 215, 2014.

[12] Gunaraj,V., Murugan, N. "Application of response surface methodology for predicting weld bead quality in submerged arc welding of pipes", Journal of Materials Processing Technology 88 (1-3), pp. $266-275,1999$. 
[13] Kumar,A., Sundarrajan, S. "Optimization of pulsed TIG welding process parameters on mechanical properties of AA 5456 Aluminum alloy weldments," Materials and Design 30, pp. 1288 - 1297, 2009.

[14] Moi, S. C., Pal, P. K., Bandyopadhyay, A., Rudrapati, R. "Determination of tungsten inert gas welding input parameters to attain maximum tensile strength of $316 \mathrm{~L}$ austenitic stainless steel", Strojnícky časopis - Journal of Mechanical Engineering 68 (3), pp. 231 - 248, 2018. DOI: $10.2478 /$ scjme-2018-0037

[15] De, D., Nandi, T., Bandyopadhyay, A. "Parametric Study for Wire Cut Electrical Discharge Machining of Sintered Titanium", Strojnícky časopis - Journal of Mechanical Engineering 69 (1), pp. 17 - 38, 2019. DOI: 10.2478/scjme-2019-0002

[16] Vasantharaja, P., Vasudevan, M. "Optimization of A-TIG welding process parameters for RAFM steel using response surface methodology", Journal of Materials: Design and Applications 232 (2), pp. 121 - 136, 2015. DOI: 10.1177/1464420715619192

[17] Kiaee, N., Aghaie-Khafri, M. "Optimization of gas tungsten arc welding process by response surface methodology", Materials and Design 54, pp. 25 - 31, 2014. DOI: 10.1016/j.matdes.2013.08.032

[18] Martinez-Conesa, E. J., Egea, J. A., Miguel, V., Toledo, C., Meseguer-Valdenebro, J. L. "Optimization of geometric parameters in a welded joint through response surface methodology", Construction and Building materials 154, pp. 105 - 114, 2017. DOI: 10.1016/j.conbuildmat.2017.07.163

[19] Dao, T. P., Huang, S. C., Thang, P. T. "Hybrid Taguchi-cuckoo search algorithm for optimization of a compliant focus positioning platform", Applied Soft Computing 57, pp. 526 - 538, 2017. DOI: 10.1016/j.asoc.2017.04.038

[20] Azizah, B. M. "Enhancement of the machining surface roughness model with cuckoo algorithm" Thesis of Master of Science, Faculty of Computing, Universiti Teknologi Malaysia, 2014.

[21] Burnwal, S., Deb, S. "Scheduling optimization of flexible Manufacturing system using cuckoo search-based approach", International Journal of Advanced Manufacturing Technology 64, pp. $951-959,2013$.

[22] Ferreira, S. L. C., Bruns, R. E., Ferreira, H. S., Matos, G. D., David, J. M., Brandao, G. C., Silva E. G. P., Portugal, L. A., Reis, P. S., Souza. A. S, Santos, W. N. L. "BoxBehnken design: An alternative for the optimization of analytical methods", Analytica Chimica Acta 597, pp. 179 - 186, 2007.

[23] Yang, X. S., Deb, S. "Cuckoo search via Levy flights", Proceeding of World Congress on Nature and Biologically Inspired Computing, India, 2009.

[24] Fister, I. Jr., Fister, D., Fister, I. “A comprehensive review of cuckoo search: variants and hybrids", Int. J. Mathematical Modelling and Numerical Optimisation 4 (4), pp. 387 $-409,2013$.

[25] Wang, T., Meskin, M., Grinberg, I. "Comparison between particle swarm optimization and Cuckoo search method for optimization in unbalanced active distribution system", IEEE International Conference on Smart Energy Grid Engineering (SEGE), pp. 14 - 19, 2017.

[26] Alam, M. S., Prima, S. S., Gupta, S. D., Razia, J. "Parameter optimization of Cuckoo Search Algorithm for Multi Dimensional Function Optimization Problem", 
Communications on Applied Electronics 7(18), pp. $6-10,2018$. DOI: $10.5120 /$ cae2018652776

[27] Mohamad, A., Zain, A. M., Bazin, N. E. N., Udin, A. "Cuckoo search algorithm for optimization problems - A literature review”, Applied Mechanics and Materials 421, pp. 502 - 506, 2013. DOI: 10.4028/www.scientific.net/AMM.421.502 